\title{
THE GREEN SPACE AND SOCIAL IMPACT IN ALMATY CITY: A CROSS-SECTIONAL DATA ANALYSIS
}

\author{
Guldana MINZHANOVA \\ Al-Farabi Kazakh National University, Faculty of Geography \& Environmental Sciences, Almaty, Kazakhstan, e-mail: Minzhanova@kaznu.kz \\ Liudmila PAVLICHENKO* \\ Al-Farabi Kazakh National University, Faculty of Geography \& Environmental Sciences, Almaty, Kazakhstan, e-mail: Pavlichenko@kaznu.kz \\ Sholpan KARBAYEVA \\ Abai Kazakh National Pedagogical University, Faculty of Environmental Sciences, Almaty, Kazakhstan, e-mail: Sh.Karbayeva@kaznpu.kz
}

Lalita BIMAGAMBETOVA

Tynyshpaev Kazakh Academy of Transport and Communications, Shevchenko Street, 97, 050000, Almaty, Kazakhstan, e-mail: Bimagambetova@kazatu.kz

Oliesia RAZDOBUDKO

Al-Farabi Kazakh National University, Faculty of Geography \& Environmental Sciences, Almaty, Kazakhstan, e-mail: Razdobudko@kaznu.kz

\begin{abstract}
Citation: Minzhanova, G., Pavlichenko, L., Karbayeva, Sh., Bimagambetova, L., \& Razdobudko, O. (2021). THE GREEN SPACE AND SOCIAL IMPACT IN ALMATY CITY: A CROSS-SECTIONAL DATA ANALYSIS. GeoJournal of Tourism and Geosites, 34(1), $251-255$. https://doi.org/10.30892/gtg.34134-645
\end{abstract}

\begin{abstract}
The theory of urban ecology tries to enhance the positive aspects of green space for humans, while at the same time decreasing the negative aspects of cities for the environment. These benefits are reflected in economic terms as they have a positive effect on real estate values, investment, tourism and the quality of life. In this study urban green space is defined as all urban land covered by vegetation of any kind. This covers vegetation on private and public grounds, irrespective of size and function, and can also include small water bodies such as ponds, lakes or streams. This study aims to find the relationship between green space abundance and social impact in particular on academic progress in Almaty city, South Kazakhstan. Data on green space, academic average point score, and nine possible confounding variables were collated. Multiple linear regression analysis was performed. Multivariate data analysis was performed to produce scatter plots that include regression lines. There was a positive relationship between the proportion of green space and better academic average scores per student after accounting for the possible confounding variables. This study provides some support for the idea that access to green space has a positive impact on academic progress, but by no means is it conclusive.
\end{abstract}

Key words: urban planning and development, academic progress, regression analysis, Kazakhstan

\section{INTRODUCTION}

It is now widely accepted that urban green space, such as parks, support and promote good mental and physical health (Diaz et al., 2006). Urban green space has been linked to stress reduction (Roe et al., 2013), improved social cohesion (Maas et al., 2009), reduced morbidity in various groups of diseases (Maas et al., 2009), recovery from mental fatigue (Taylor and Kuo, 2009; Berman et al., 2012) and the promotion of exercise (Bell et al., 2008; Alcock, 2014) amongst other things. There is also a growing body of evidence for a positive relationship between physical and mental health and academic attainment. For example, the vast majority of published articles on the matter have reported positive associations between physical activity and cognition (Hillsdon et al., 2006; Howie and Pate, 2012). A large number of researchers in the field now believe that there is sufficient evidence to introduce school physical activity policies that have the potential to improve academic results (Howie and Pate, 2012; Mynbayeva and Yelbayeva, 2020). Studies on the effects of mental health on academic success have found that mental health issues, such as anxiety and depression, are significant predictors of lower grades and increased chances of dropping out (Eisenberg et al., 2009; McLeod et al., 2012). One study also concluded that students whose mental health improved over their time at school made better academic progress than students whose mental health did not improve or worsened (Murphy et al., 2015).

Other researcg suggests that children living in areas with more green space around them may have better spatial working memory (Flouri et al., 2019; Taysum et al., 2020). Spatial working memory is a measure of how effective people are at orientation and recording information about their environment. It enables us to navigate through a city or remember the position of objects. The same research found that a lower quantity of neighbourhood green space was related to poorer spatial working memory, and this relationship was the case in both deprived and nondeprived neighbourhoods (Wolch et al., 2014; Flouri et al., 2019). Dadvand et al. (2015) assess the association between indicators of exposure to green space and measures of cognitive development, including working memory (the system that holds multiple pieces of transitory information in the mind where they can be manipulated), superior working memory (working memory that involves continuous updating of the working memory buffer), and inattentiveness in primary schoolchildren (Mynbayeva and Pogosian, 2014; Dadvand et al., 2015).

Within cities there is substantial potential to increase the ecosystem performance of green spaces (Tratalos et al., 2007), and within urban ecology there is a growing understanding of the functioning of natural systems within the urban environment (Kaye et al., 2006; Andersson, 2007). A focus on ecosystem services could lead to a better understanding of the connections between humans and the environment. Therefore, ecosystem services must be explicitly integrated in decisionmaking (Daily et al., 2009; Movkebayeva et al., 2020). Ecosystem services could be used as criteria in green space planning, both to evaluate and to provide goals for management and planning. This is often done for one or two ecosystem services already. For example, some cities in developed countries are using the water regulation services of urban green as an extra asset in their green management. Approaches using multiple ES criteria are scarce. These ecosystem services criteria should be combined with other criteria in green space planning. Recently Nuissl et al. (2009) proposed such a combined framework to evaluate land use change. They 
suggested an assessment that takes several criteria into account, including many ecosystem services. This could lead to an analysis that not only provides a more integrative way of looking at urban areas, but also gives new insights within a discussion that has a strong focus on spatial criteria (Nuissl et al., 2009; Koshim et al., 2020). The presence of green spaces within cities varies, but is diminishing with the current trend of urban compaction (Fuller and Gaston, 2009; Aliyeva et al., 2020). The dominance of impervious surfaces also changes the local climate, and creates an urban heat island effect. Together with direct human actions these differences have a profound impact on urban biodiversity and the provisioning of ecosystem services (Shandas et al., 2008; Aktymbayeva et al., 2020). Despite this chain of evidence, there has been very little work done on establishing the relationship between access to green space and academic achievement. In this study urban green space is defined as all urban land covered by vegetation of any kind. This covers vegetation on private and public grounds, irrespective of size and function, and can also include small water bodies such as ponds, lakes or streams (Artykbaev et al., 2020). This study aims to identify whether the positive effects of urban green space listed above extend to improved academic attainment. Such work is important as a better understanding of how academic achievement is affected by environmental factors may help to improve learning outcomes. This is particularly relevant given that in recent years, opportunities for spontaneous and regular contact with the natural world have decreased significantly for many children.

\section{METHODOLOGY}

Part of the effect of green space on academic progress may be the result of direct or indirect selection. Direct selection takes place when people's academic success influences their chances of living in a favourable environment. Indirect selection takes place when people with certain characteristics related to wellbeing (such as income) can afford to live in a favourable environment. Almaty city was selected for the case study of the effect of green space on academic progress. Almaty is the largest megalopolis of Kazakhstan with a populati on of almost 2 bln and there are 40 universities offering 901 study programs. The city is located in the southern part of Kazakhstan and surrounded by mountains. The significant area of all urban land covered by vegetation of any kind (Figure 1).

It is important when analyzing the strength of the relation, to take the possibility of selection into account and to control for this. Publicly available data for the following variables were obtained from the Kazakh National Datastore for Almaty city and other resources (Karatayev et al., 2016; Karatayev et al., 2017a): \% area that is green space (2015), average point score per student (2018/19), population density (2019), \% of residents that students at Al-Farabi Kazakh National University (2019), employment rate of 16-64 year olds (2019), median house price (2019), median household income estimate (2018/19), \% of children in reception year that are obese (2016/17 to 2018/19), \% of children in year 6 who are obese (2016/17 to 2018/19), and \% unauthorized absence in all schools (2019).

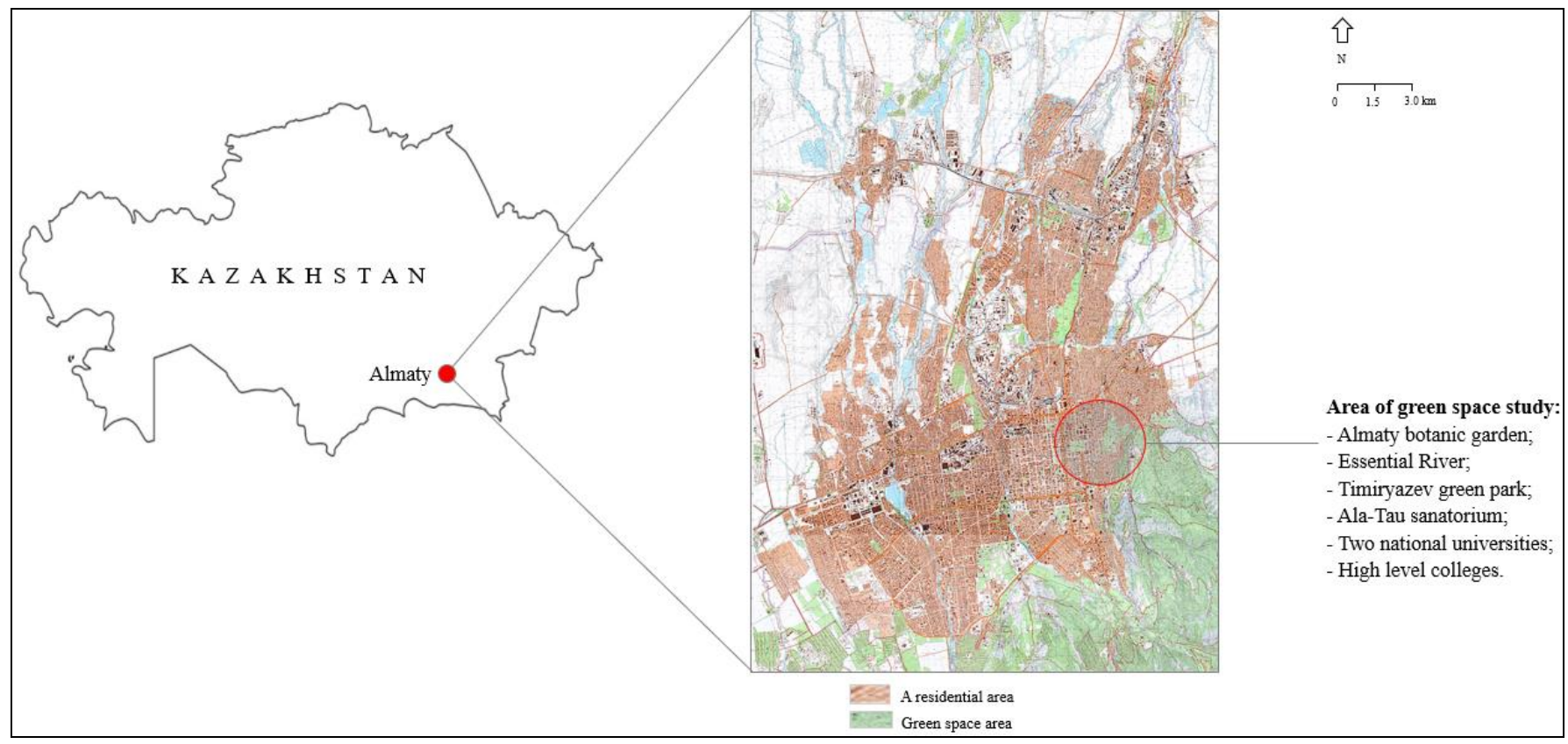

Figure 1. Green space and residential area of Almaty city

Multiple linear regression analysis was then carried out on the data. All procedures were carried out using the RegressIt add-in on Microsoft Excel. If the data are created by numerous variables, the analytical methods become very complicated. If a function is a linear function containing two or more variables, the multiple linear regression method is an excellent approach to fit data. Multivariate data analysis was carried out, producing descriptive statistics and scatter plots that include regression lines. The methods of analysis include changing the number of sample points to derive the least sample number required for solving the accurate estimated parameter values. Besides, different high-order lens distortion parameters were ignored, and only the various modes of low-order parameters were regressed to compare their effects on the overlay analysis results. In our case, let $y$ be the linear fitting function of the $m$ number of virables (see Breiman and Friedman, 1997; Toriello and Vielma, 2012),

$$
x_{1}, x_{2, n,} x_{m} \text { to: } y\left(x_{1}, x_{2}, \ldots, x_{m}\right)=a_{0}+a_{1} x_{1}+a_{2} x_{2}+\cdots+a_{m} x_{m},
$$

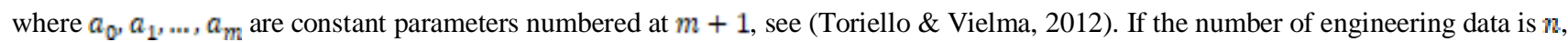
then the sum of the square of error is: $\quad S_{Y}=\sum_{i=1}^{n}\left(y_{i}-a_{0}-a_{1} x_{1 i}-a_{2} x_{2 i}-\cdots-a_{m} x_{m i}\right)^{2}$

Derive the derivatives of the above equation with respect to each parameter (see Toriello \& Vielma, 2012), and let:

$$
\frac{d s_{F}}{d a_{0}}=\frac{d s_{F}}{d a_{1}}=m=\frac{d s_{F}}{d a_{i m}}=0
$$

Then matrix equation can be derived as follows (see Breiman and Friedman, 1997; Toriello and Vielma, 2012): 


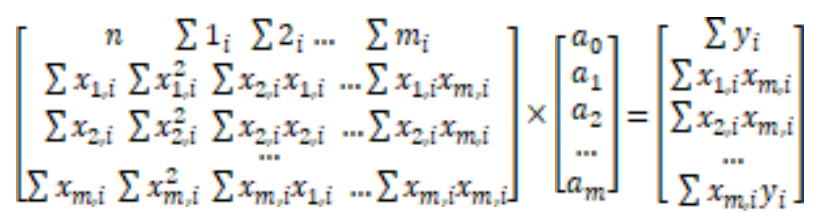

The elements $a_{0}, a_{1}, a_{2} \ldots a_{m}$ are the equation parameters estimated by fitting engineering data. The $S D$ of multiple linear regression (see Toriello and Vielma, 2012) is:

$$
\partial_{R}=\sqrt{\frac{s_{F}}{n-m-1}}
$$

Therefore, the sample number $n$ must be, at least, larger than $m+1$. Otherwise, $S D$ will be invalid if the denominator of the square root in $S D$ is equal to or smaller than zero. The multiple linear regression method includes planning the number of sample points, exploring differences in the numerical order of the error parameters in the overlay accuracy model, and the effect of ignoring different high-order lens distortion parameters on overlay. To obtain accurate estimated values of error parameters, the number of sample points increases exponentially along with the increase in the number of orders of parameters in the overlay accuracy model. When estimated values of the error parameter of loworder distortion parameters of overlay have a numerical order far higher than that of high-order distortion parameters, the high-order distortion parameters can be ignored. In this case, excellent overlay improvements can still be achieved.

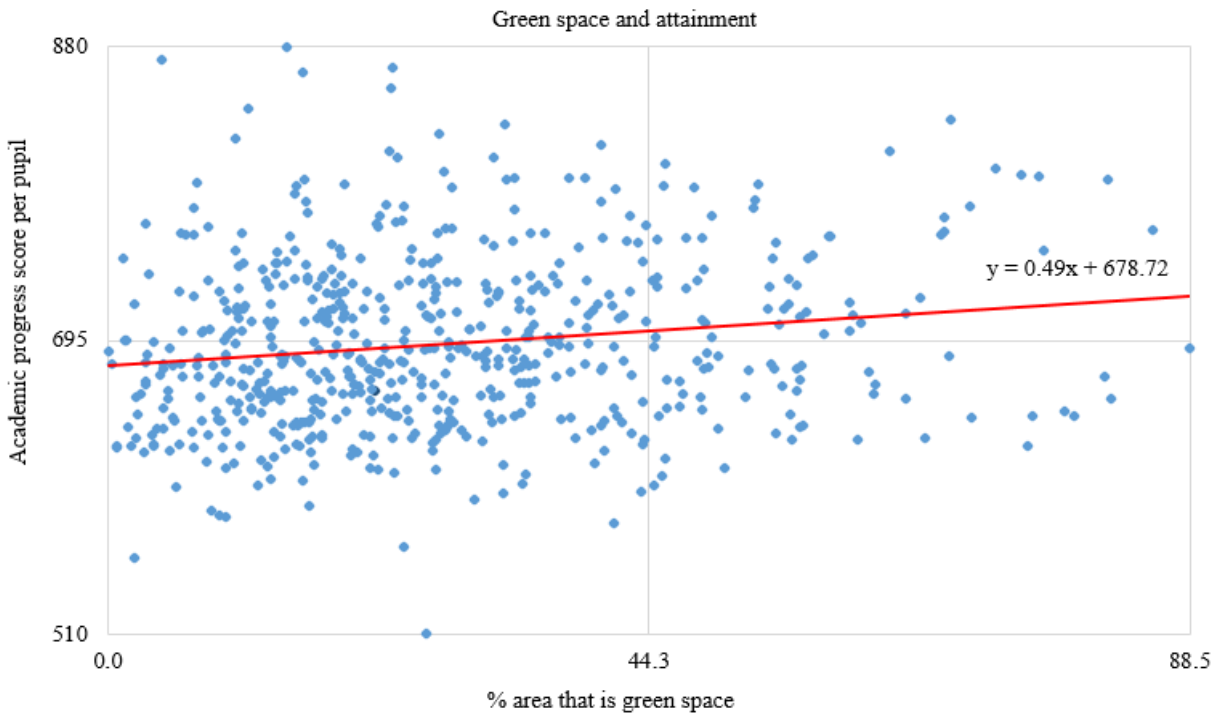

Figure 2. The relationship between green space area and academic progress
RESULTS

As can be seen in Table 1 , the regression analysis showed a slight positive relationship between the proportion of green space in a ward and better academic point scores per student after accounting for the possible confounding variables; the coefficient was 0.090 with a P-value of 0.5 . This has been represented graphically in Figure 2 . Unsurprisingly, the variable with the largest coefficient magnitude was percentage of unauthorised absences in schools; this coefficient was three orders of magnitude larger than the coefficient for percentage area that is green space. There was huge variation in the orders of magnitude of the coefficients. Percentage area that is green space had the coefficient with the sixth largest magnitude out of the 10 variables included in the model, and the third largest positive coefficient.

Only two coefficients (percentage of reception children that are obese and population density) were statistically significant according to the conventional 0.05 limit (Nuzzo, 2014). While these results do not oppose the theory that access to green space has positive effects on academic attainment, the support this study provides is weak and the results are by no means conclusive. The size of the regression coefficient for each independent variable gives the size of the effect that variable is having on better academic point scores per pupil.

Table 1. The proportion of green space and better academic point scores

\begin{tabular}{|c|c|c|c|c|}
\hline \multicolumn{5}{|c|}{ Regression Statistics: $(10$ variables, $\mathrm{n}=605)$} \\
\hline & R-Squared & Ad.R-Sqr. & Std.Err. & Std.Dev. \\
\hline & 0.330 & 0.319 & 44.020 & 53.330 \\
\hline \multicolumn{5}{|c|}{ Coefficient Estimates: $(10$ variables, $\mathrm{n}=605)$} \\
\hline Variable & Coeff. & Std.Err. & t-Stat. & P-value \\
\hline$\%$ of unauthorised absence in schools & -77.000 & 5.575 & -13.813 & 0.000 \\
\hline$\%$ of reception children that are obese & -2.319 & 0.993 & -2.335 & 0.020 \\
\hline$\%$ of year six children that are obese & -0.660 & 0.616 & -1.073 & 0.284 \\
\hline Population density & -0.001290 & 0.000828 & -2.055 & 0.040 \\
\hline Median household income estimates & -0.001153 & 0.000786 & -1.467 & 0.143 \\
\hline Median house price & 0.000019 & 0.000020 & 0.945 & 0.345 \\
\hline$\%$ area that is green space & 0.090 & 0.146 & 0.617 & 0.537 \\
\hline Employment rate & 0.212 & 0.530 & 0.400 & 0.689 \\
\hline Constant & 838.989 & 43.141 & 19.448 & 0.000 \\
\hline Variable & Lower $95 \%$ & Upper $95 \%$ & Std.Dev. & Std.Coeff. \\
\hline$\%$ of unauthorised absence in schools & -87.949 & -66.052 & 0.338 & -0.489 \\
\hline$\%$ of reception children that are obese & -4.269 & -0.369 & 3.109 & -0.135 \\
\hline$\%$ of year six children that are obese & -1.869 & 0.549 & 5.146 & -0.064 \\
\hline Population density & -0.002522 & -0.000057 & 4.849 & -0.117 \\
\hline Median household income estimates & -0.002697 & 0.000390 & 6.504 & -0.141 \\
\hline Median house price & -0.000021 & 0.000059 & 182.662 & 0.066 \\
\hline$\%$ area that is green space & -0.196 & 0.376 & 17.525 & 0.030 \\
\hline Employment rate & -0.829 & 1.253 & 6.478 & 0.026 \\
\hline Constant & 754.261 & 923.717 & & \\
\hline
\end{tabular}

Regression Statistics: (10 variables, $\mathrm{n}=605)$
The positive relationship found was very orders of magnitude smaller than that of percentage of unauthorised absences in schools. The $\mathrm{P}$ value was not statistically significant according to convention, so, whilst this might take away from the certainty of the conclusion that there is a small but positive relationship between access to green space and academic attainment, it should not discourage further studies on the subjects that use different methods. This is partly because many in the fields that traditionally use statistical testing have claimed that they do not accurately reflect the quality of evidence and may lead to false positives (Trafimow and Marks, 2015). P values have also been criticized for deflecting attention from the actual size of the effect (Nuzzo, 2014). For these reasons, the $P$ values in this study are of secondary importance to the size and plausibility of the effect of green space on academic attainment. Although the R2 value was relatively low, 
it is of minor importance here as no predictions are being made. Another reason to interpret the results of this analysis with caution is that they contradict the results of numerous large studies that have shown that variables such as family income have significant and substantial impacts on attainment (Moore et al., 2013). Although, arguably, a more rigorous approach to answering this question may have been to group wards that are similar in all respects apart from their proportion of green space and then to perform a t-test, this technique was rejected due to the difficulty in grouping wards, which would have required subjective decisions to be made. Despite the lack of previous literature directly related to the link between access to green space and academic attainment, this study does have some strengths.

Firstly, the publicly accessible data allowed for many variables that are known to impact on attainment, such as wealth and ethnic background (Moore et al., 2013), to be accounted for. This is really important, as it allowed the effects of access to green space to be isolated as much as possible and thus gives a much more realistic picture of the impact of access to green space. The large sample size and the variation in demographics and geography between wards is also a credit to the study. It is also important to note the possible limitations of this study. Firstly, uncertainty is introduced by conducting analysis at ward level. As a result of this, length of residence as a measure of the degree of exposure or access to green space or possible lags in outcomes were not accounted for. It also means that no individual-level conclusions can be made, and that some differences in how some subpopulations are affected, such as how different genders are affected differently, could not be accounted for. As noted above, the data were collected between 2010 and 2015. Ideally, if annual data on the independent variables included were available for 2000-2015, changes in the demographics and green space of wards could have been considered. The dataset was derived from a large-scale public data source, which does not account for small privately-owned green spaces. Therefore, this study only looks at the effects of large, public green spaces. It is plausible that these spaces, such as gardens, do have an effect on mental and physical health (Nutsford et al., 2013) and attainment, and so this should be taken into consideration when interpreting results.

\section{DISCUSSION AND CONCLUSION}

This study shows that urban planning and university campus planning programs should include aspect for green space development and policy makers should take the amount of green space in the living environment into account when endeavoring to improve the social situation of the population, especially in urban environments. Like most countries, Kazakhstan is concerned with the future development and prosperity of constituent cities and regions; how is the modernisation and urbanisation of the country to be governed; how can people prosper, and social cohesion and environmental protection be ensured; how is green campus university programs should be integrated into urban policy development. In all countries, these questions must be superimposed on existing institutions, societal norms, state budgets and cultural practice. The major cities of Kazakhstan are also modernising very rapidly. City institutions are transitioning from those of a young, post-Soviet country, to those of an established independent nation. This includes building the capacity of local government and, crucially, the cultivation of a latent civil society dialogue. There is a consistent concern about the ability of Kazakh civil society to participate in decision making on issues such as urban water management, air quality, waste management and urban planning.

Access to green environments on universities, schools grounds or in universities, schools attendance areas could thus enhance both student and school-level academic success while lack of such access could hinder success. This in turn could influence the future well-being of urban populations via impacts on employment and socioeconomic status associated with poor educational outcomes. This notion is particularly interesting in the context of intensively-developed urban environments with little vegetation or green space; environments where student academic performance, particularly that of disadvantaged groups, is often poor. The limited evidence that exists in this area indicates that nature on and around university campuses can indeed impact the academic performance of entire student bodies. For example, high schools with views of trees and shrubs have been found to have higher average standardized test scores and graduation rates, more students going to college, and lower delinquency rates than other schools (Matsuoka, 2010). Additionally, levels of vegetation around universities have been found to exhibit a positive association with third-grade reading and mathematics scores on standardized tests (Wu et al., 2014). The connection between urban nature and university-level academic performance, however, is currently under-explored, and defining relationships between urban vegetation and university performance will require considerably more research. Key questions that remain center on identifying the locations in which natural landscape elements impact student performance, how different natural landscape elements influence academic performance, and the levels and types of exposure to nature that relate to student academic performance.

In conclusion, this study provides some support for the idea that access to green space has a positive impact on academic progress, but by no means is it conclusive. We hypothesized that the relation between green space and academic success would be stronger for people who are assumed to spend more time in green areas. Furthermore, the analyses show that the amount of green space is more strongly related to perceived general academic progress than urbanity. This research has shown that green space is more than just a luxury, and the development of green space should therefore be allocated a more central position in spatial planning policy. It highlights the need for further work, in particular, longitudinal studies. A longitudinal study that considers possible confounding variables as well as proximity and access to green space and academic attainment over the course of pupils' school career using remotely sensed images would allow for individual level conclusions and further isolation of the effects of green space as data on other possible confounding variables could be collected. Using remotely sensed images could, depending on the spatial resolution and classification tech nique, include small scale privately owned green spaces such as gardens. More information on how green space affects mental and physical health across the life course could help to determine the relative effects of green spaces on school pupils compared to other age groups. This should help to determine whether improved academic attainment is a valid argument for maintaining and supporting green spaces.

\section{Acknowledgment}

The paper was written as part of cooperation within UK-Kazakhstan Newton Fund Researcher Links Grants to participate in "Sustainable Urbanization in Kazakhstan" workshop, organized on September 25-29, 2019 in Kazakhstan, Nursultan by University of York (UK) and Gumilyov Eurasian National University (Kazakhstan).

\section{REFERENCES}

Aktymbayeva, A., Assipova, Zh., Moldagaliyeva, A., Nuruly Y., \& Koshim, A. (2020). Impact of small and medium-sized tourism firms on employment in Kazakhstan. GeoJournal of Tourism and Geosites, 32(4), 1238-1243. https://doi.org/10.30892/gtg.32407-563

Alcock, I., White, M.P., Wheeler, B.W., Fleming, L.E., \& Depledge, M.H. (2014). Longitudinal effects on mental health of moving to greener and less green urban areas. Environmental science \& technology, 48(2), 1247-1255. https://doi.org/10.1021/es403688w

Aliyeva, Z., Sakypbek, M., Aktymbayeva, A., Assipova, Z., \& Saidullayev, S. (2020). Assessment of recreation carrying capacity of ile-alatau national park in Kazakhstan. GeoJournal of Tourism and Geosites, 29 (2), 460-471. https://doi.org/10.30892/gtg.29207-482

Andersson, E., Barthel, S., \& Ahrné, K. (2007). Measuring social-ecological dynamics behind the generation of ecosystem services. Ecological applications, 17(5), 1267-1278. https://doi.org/10.1890/06-1116.1 
Artykbaev, D., Baibolov, K., \& Rasulov, H. (2020). Stability analysis of fine soils from a road project, M32 Samara-Shymkent (Russia-Kazakhstan). International Journal, 19(76), 205-212. https://doi.org/10.21660/2020.76.78503

Bell, S., Hamilton, V., Montarzino, A., Rothnie, H., Travlou, P., \& Alves, S. (2008). Greenspace and quality of life: a critical literature review. Greenspace Scotland, Stirling.

Berman, M.G., Kross, E., Krpan, K.M., Askren, M.K., Burson, A., Deldin, P.J., Kaplan., S., Sherdell, L., Gotlib, I.H., \& Jonides, J. (2012). Interacting with Nature Improves Cognition and Affect for Individuals with Depression. Journal of Affective Disorders, 140, 300-305. https://doi.org/10.1016/j.jad.2012.03.012

Breiman, L., \& Friedman, J.H. (1997). Predicting multivariate responses in multiple linear regression. Journal of the Royal Statistical Society: Series B (Statistical Methodology), 59(1), 3-54.

Dadvand, P., Nieuwenhuijsen, M.J., Esnaola, M., Forns, J., Basagaña, X., Alvarez-Pedrerol, M., \& Jerrett, M. (2015). Green spaces and cognitive development in primary schoolchildren. Proceedings of the National Academy of Sciences, 112(26), 7937-7942. https://doi.org/10.1073/pnas.1503402112

Daily, G.C., Polasky, S., Goldstein, J., Kareiva, P.M., Mooney, H.A., Pejchar, L., \& Shallenberger, R. (2009). Ecosystem services in decision making: time to deliver. Frontiers in Ecology and the Environment, 7(1), 21-28. https://doi.org/10.1890/080025

Diaz, S., Fargione, J., Chapin, F.III.S., \& Tilman, D. (2006). Biodiversity Loss Threatens Human Well-Being. PLoS Biology, 4, 277. https://doi.org/10.1371/journal.pbio.0040277

Eisenberg, D., Golberstein, E., \& Hunt, J.B. (2009). Mental Health and Academic Success in College. The B.E. Journal of Economic Analysis \& Policy, 9: Article 40. https://doi.org/10.2202/1935-1682.2191

Flouri, E., Papachristou, E., \& Midouhas, E. (2019). The role of neighbourhood greenspace in children's spatial working memory. British Journal of Educational Psychology, 89(2), 359-373. https://doi.org/10.1111/bjep.12243

Fuller, R.A., \& Gaston, K.J. (2009). The scaling of green space coverage in European cities. Biology letters, 5(3), 352-355. https://doi.org/10.1098/rsbl.2009.0010

Hillsdon, M., Panter, J., Foster, C., \& Jones, A. (2006). The relationship between access and quality of urban green space with population physical activity. Public health, 120(12), 1127-1132. https://doi.org/10.1016/j.puhe.2006.10.007

Howie, E.K., \& Pate, R.R. (2012). Physical activity and academic achievement in children: A historical perspective. Journal of Sport and Health Science, 1, 160-169. https://doi.org/10.1016/j.jshs.2012.09.003

Karatayev, M., Hall, S., Kalyuzhnova, Y., \& Clarke, M.L. (2016). Renewable energy technology uptake in Kazakhstan: Policy drivers and barriers in a transitional economy. Renewable and Sustainable Energy Reviews, 66, 120-136. https://doi.org/10.1016/j.rser.2016.07.057

Karatayev, M., Kapsalyamova, Z., Spankulova, L., Skakova, A., Movkebayeva, G., \& Kongyrbay, A. (2017a). Priorities and challenges for a sustainable management of water resources in Kazakhstan. Sustainability of Water Quality and Ecology, 9, 115-135. https://doi.org/10.1016/j.swaqe.2017.09.002

Karatayev, M., Rivotti, P., Mourão, Z.S., Konadu, D.D., Shah, N., \& Clarke, M. (2017b). The water-energy-food nexus in Kazakhstan: challenges and opportunities. Energy Procedia, 125, 63-70. https://doi.org/10.1016/j.egypro.2017.08.064

Kaye, J.P., Groffman, P.M., Grimm, N.B., Baker, L.A., \& Pouyat, R.V. (2006). A distinct urban biogeochemistry?. Trends in Ecology \& Evolution, 21(4), 192-199. https://doi.org/10.1016/j.tree.2005.12.006

Koshim, A.G., Sergeyeva, A.M., Bexeitova, R.T., \& Aktymbayeva, A.S. (2020). Landscape of the Mangystau region in Kazakhstan as a geomorphotourism destination: a geographical review. GeoJournal of Tourism \& Geosites, 29(2). 7. https://doi.org/10.30892/gtg.29201-476

Maas, J., Verheij, R.A., de Vries, S., Spreeuwenberg, P., \& Schellevis, F.G. (2009). Morbidity is related to a green living environment. Journal of Epidemiology and Community Health, 63, 967-973. https://doi.org/10.1136/jech.2008.079038

Matsuoka, R. (2010). Student performance and high school landscapes: Examining the links. Landscape and Urban Planning, 97, 273-82. https://doi.org/10.1016/j.landurbplan.2010.06.011

McLeod, J.D., Uemura, R., \& Rohrman, S. (2012). Adolescent Mental Health, Behavior Problems, and Academic Achievement. Journal of Health and Social Behaviour, 53, 482-497. https://doi.org/10.1177/0022146512462888

Mitchell, R., \& Popham, F. (2008). Effect of exposure to natural environment on health inequalities: an observational population study. The Lancet, 372, 16551660. https://doi.org/10.1016/s0140-6736(08)61689-x

Moore, J., Sanders, J., \& Higham, L. (2013). Literature review of research into widening participation to higher education. ARC Network: London.

Movkebayeva, G., Aktymbayeva, A., Tyurina, Y., Baikadamov, N., Beketova, K., Troyanskaya, M., \& Imangaliyeva, A. (2020). Energy Security and Sustainability in Eurasian Economic Union in the Terms of Economic Growth: The Case of Kazakhstan's Energy Sector up to 2040 Perspectives. International Journal of Energy Economics and Policy, 10(2), 497-503. https://doi.org/10.32479/ijeep.9073

Murphy, J.M., Guzman, J., McCarthy, A.E., Squicciarini, A.M., George, M., Canenguez, K.M., Dunn, E.C., Baer, L., Simonsohn, A., Smoller, J.W., \& Jellinek, M.S. (2015). Mental Health Predicts Better Academic Outcomes: A Longitudinal Study of Elementary School Students in Chile. Child Psychiatry and Human Development, 46, 245-256. https://doi.org/10.1007/s10578-014-0464-4

Mynbayeva, A., \& Pogosian, V. (2014). Kazakhstani School Education Development from the 1930s: History and Current Trends. Italian Journal of Sociology of Education, 6(2). https://doi.org/10.14658/pupj-ijse-2014-2-7

Mynbayeva, A., \& Yelbayeva, Z. (2020). Modern Trends of Involving Kazakhstan'Schoolchildren and Teachers in School Management. Italian Journal of Sociology of Education, 12(1). https://doi.org/164-181.10.14658/pupj-ijse-2020-1-10

Nuissl, H., Haase, D., Lanzendorf, M., \& Wittmer, H. (2009). Environmental impact assessment of urban land use transitions - A context-sensitive approach Land use policy, 26(2), 414-424. https://doi.org/10.1016/j.landusepol.2008.05.006

Nutsford, D., Pearson, A.L., \& Kingham, S. (2013). An ecological study investigating the association between access to urban green space and mental health. Public Health, 127, 1005-1011. https://doi.org/10.1016/j.puhe.2013.08.016

Nuzzo, R. (2014). Scientific Method: Statistical Errors. Nature, 506, 150-152. https://doi.org/10.1038/506150a

Roe, J.J., Ward Thompson, C., Aspinall, P.A., Brewer, M.J., Duff, E.I., Miller, D., Mitchell, R., \& Clow, A. (2013). Green Space and Stress: Evidence from Cortisol Measures in Deprived Urban Communities. International Journal of Environmental Research and Public Health, 10, 4086-4103. https://doi.org/10.3390/ijerph10094086

Shandas, V., Graybill, J.K., \& Ryan, C.M. (2008). Incorporating ecosystem-based management into urban environmental policy: a case study from western Washington. Journal of Environmental Planning and Management, 51(5), 647-662. https://doi.org/10.1080/09640560802211037

Taylor, A.F., \& Kuo, F.E. (2009). Children with attention deficits concentrate better after walk in the park. Journal of Attention Disorders, 12: 402-409. https://doi.org/10.1177/1087054708323000

Taysum, A., Arar, K., Chopra, P., Imam, H., Harrison, K., McNamara, G., \& McGuinness, S.J. (2020). Optimising Well-Being and Learning Through Participatory Processes and Practices: an International Comparative Analysis of Ten Groundwork Case-Studies in Schools. Italian Journal of Sociology of Education, 12(1). https://doi.org/10.14658/pupj-ijse-2020-1-11

Toriello, A., \& Vielma, J.P. (2012). Fitting piecewise linear continuous functions. European Journal of Operational Research, 219(1), 86-95. https://doi.org/10.1016/j.ejor.2011.12.030

Trafimow, D., \& Marks, M. (2015). Editorial, Basic and Applied Social Psychology, 37, 1-2. https://doi.org/10.1080/01973533.2015.1012991

Tratalos, J., Fuller, R.A., Warren, P.H., Davies, R.G., \& Gaston, K.J. (2007). Urban form, biodiversity potential and ecosystem services. Landscape and urban planning, 83(4), 308-317. https://doi.org/10.1016/j.landurbplan.2007.05.003

Wolch, J.R., Byrne, J., \& Newell, J.P. (2014). Urban green space, public health, and environmental justice: The challenge of making cities 'just green enough'. Landscape and urban planning, 125, 234-244. https://doi.org/10.1016/j.landurbplan.2014.01.017

Wu, C., McNeely, E., Cedeño-Laurent, J., Pan, W., Adamkiewicz, G., Dominici, F., Lung, S., Su, H., \& Spengler, J. (2014). Linking student performance in massachusetts elementary schools with the "greenness" of school surroundings using remote sensing. PLoS ONE, 9, 1-9. https://doi.org/10.1371/journal.pone.0108548 